DE DE GRUYTER OPEN

G

10.1515/topling-2016-0004

\title{
A cross cultural analysis of conjuncts as indicators of the interaction and negotiation of meaning in research articles
}

\author{
Renata Povolná \\ Masaryk University, Czech Republic
}

\begin{abstract}
The role of English as a global lingua franca of academia has become indisputable in the on-going process of internationalization of all scholarship, even though the majority of writers and readers of academic texts are non-native speakers of English. Thus it is questionable whether there is any justification for imposing on international academic communication written in English the style conventions typical of the dominant Anglophone discourse community. Recommendations usually comprise qualities such as clarity, economy, linearity and precision in communication (cf. Bennett, 2015), which can be achieved, among other means, by certain overt guiding signals including conjuncts (Quirk et al., 1985).

Accordingly, the aim of this paper is to reveal cross-cultural variation in the use of these important text-organizing means as it is believed that conjuncts can enhance the interaction and negotiation of meaning between the author and prospective readers of academic texts. The paper explores which semantic relations holding between parts of a text tend to be expressed overtly by conjuncts and which semantic classes, such as appositive, contrastive/concessive, listing and resultive conjuncts, contribute most to the interactive and dialogic nature of written academic discourse. The data are taken from research articles (RAs) selected from two journals, one representing academic discourse written by native speakers of English (Applied Linguistics) and the other representing academic texts written in English by Czech and Slovak scholars (Discourse and Interaction).
\end{abstract}

\section{Key words}

cross-cultural analysis, conjuncts, interaction, negotiation of meaning, written academic discourse, style conventions, Anglophone writers, Czech and Slovak writers

\section{Introduction}

In the process of the increasing internationalization of all scholarship it is evident that English unavoidably performs the role of a global lingua franca for all academic communication. As evidenced by many studies on written academic discourse (e.g. Chamonikolasová, 2005; Stašková, 2005; Mur-Dueňas, 2008; Vogel, 2008; Bennett, 2010; Perez-Llantada, 2011 ; Schmied, 2011 ;
Wagner, 2011; Dontcheva-Navratilova, 2012; Povolná, 2012; 2015), there is cross-cultural variation both in the form and content of academic texts produced by writers from different cultural and language backgrounds. It is assumed that this variation results mainly from the influence of writing habits and culture- and language-specific conventions which authors working in different research fields transfer from their mother tongues to 
academic texts they write in English as an additional language (Hedgcock, 2005).

Scholars from different cultural and language backgrounds mostly apply the genre of research articles (RAs) for conveying scholarly issues to an academic audience, since "publication [in English in particular] can be seen as documentary evidence that the writer qualifies for membership in the target discourse community" (Swales, 1990, p.7). Thus the use of English as an additional language has become an important prerequisite for researchers who intend to present their research findings internationally and thus become recognized in their respective research fields within the international academic community. Since the writing of scholarly texts in one's native language, such as Czech or Slovak, has become of minor importance, scholars from non-Anglophone backgrounds undergo what is sometimes called a process of "secondary socialization" (Mauranen, Hynninen and Ranta, 2010, p.184), i.e. the process of developing academic credentials within their non-native environment.

As already stated, the majority of writers and readers of scholarly texts written in English are non-native speakers. Thus the question arises whether there is any justification for imposing on international academic communication written in English the style conventions typical of the dominant Anglophone discourse community and whether qualities such as clarity, economy, linearity and precision in communication should be viewed from the perspective of "the native speaking minority" (Mauranen, Hynninen and Ranta, 2010) or from the perspective of those who come from communities that speak other languages (the Slavonic languages Czech and Slovak in the case of this paper).

Academic texts, including RAs written by Anglophone authors, are usually considered dialogic, thus providing space for interaction and negotiation of meaning between the author(s) and prospective reader(s). By comparison, academic texts written in some Central European languages tend to be monologic and less interactive (e.g. Duszak, 1997; Chamonikolasová, 2005; Stašková, 2005; Povolná, 2015). This, of course, also applies to RAs by Czech and Slovak writers which are at the core of this study. It is worth noting that similar claims have been made for other European languages, for example, Portuguese (Bennett, 2010) and Spanish (Pérez-Llantada, 2011). Anglophone academic texts are generally considered more reader-friendly owing to their overall linear textual organization through clear division into chapters, sections and subsections, chapter and section headings and application of overt guiding signals on form and content which, quite naturally, include the use of textorganizing means such as conjuncts.

\section{The interactive and dialogic nature of written academic discourse}

In the production of written texts authors tend to "draw on and incorporate ideas and forms from [their] past experiences of [other] texts" (Hyland, 2004, p.80). Therefore, texts in general and academic texts in particular are unavoidably interactive and dialogical in the sense that any part of the text is associated in a complexly organized chain of other parts of the text(s) with which it enters into one relation or another. Different texts, or parts of texts, have a certain degree of what can be called "dialogization" (Bakhtin, 1986 cited in Fairclough, 2003, p.42), since for any particular text or part of a text, "there is a set of other texts and a set of voices which are potentially relevant, and potentially incorporated into the text" (Fairclough, 2003, p.47). Texts can be defined as "the visible evidence of a reasonably self-contained purposeful interaction between one or more writers and one or more readers, in which the writer(s) control the interaction and produce most of (characteristically all) the language" (Hoey, 2001, p.11). This is in agreement with Bakhtin's view (1986) that writing is always an ongoing dialogue between the author(s) and reader(s) and Fairclough's statement that "texts are inevitably and unavoidably dialogical" (2003, p.42).

As regards written academic discourse, scholars enter a permanent dialogue with others working in the same research field, "since real academic discourse is a constant development of intertextuality" (Schmied, 2011 , p.5). Authors can let other researchers' voices be heard either directly through direct quotations of their opinions, attitudes and approaches, or more indirectly by means of 
paraphrases or reported speech, both of which are among the most explicit techniques representing intertextuality (Bazerman, 2004). In conformity with Fairclough it is supposed that "when the speech or writing or thought of another is reported, two different texts, two different voices, are brought into dialogue, and potentially two different perspectives, objectives, interests and so forth" (Fairclough, 2003, pp.48-49). It is at this point that linking devices such as conjuncts come to perform an important role. By virtue of their specific meanings they enable the expression of semantic relations between different parts of texts, thus operating as markers of intertextuality, i.e. "the explicit and implicit relations that a text or utterance has to prior, contemporary or future texts" (Bazerman, 2004, pp.86-88), and contributing to the interactive and dialogic nature of otherwise rather monologic written texts.

\section{Conjuncts}

Conjuncts, which can be classified as 'metatextual elements' or simply 'connectors' (Mauranen, 1993), allow the author to step in overtly "to make his or her presence felt in the text, to provide guidance to the readers with respect to how the text is organized, to what functions different parts of it have, and what the author's attitudes to the propositions are" (Mauranen, 1993, p.9). The guiding role of conjuncts entails signalling a particular relation between the possible interpretation of parts of a text, i.e. the unit they introduce and are part of, and the prior, not necessarily immediately adjacent unit. By indicating how the author intends to relate the coming message to the previous part of the text and by conveying logical linkage between ideas expressed in texts, conjuncts perform important text-organizing functions and are therefore viewed primarily as cohesive means which "reflect underlying connections between propositions" (Schiffrin, 1987, p.61). Conjuncts - included in Halliday and Hasan among "conjunctive elements" - "are cohesive not in themselves but indirectly, by virtue of their specific meanings" (1976, p.226).

Apart from establishing cohesion, conjuncts enhance the readability of texts because a text is usually processed and interpreted more easily if the relations between its parts are expressed overtly (Haberlandt, 1982). This is closely related to the perception of coherence, which is understood here as "the result of the interpretation process" (Tanskanen, 2006, p.20). As formulated by Tanskanen, "coherence ... resides not in the text, but is rather the outcome of a dialogue between the text and its listener or reader" (2006, p.7). Coherence in spoken discourse can be negotiated on the spot by the discourse participants (Povolná, 2009, DontchevaNavratilova, 2012), but coherence in written discourse cannot be negotiated in the same way. The context is split (Fowler 1986) and, consequently, the writer - who wants to achieve his communicative goals - has to anticipate the "expectations of the reader and to use explicit signals" (DontchevaNavratilova, 2007, p.128), including conjuncts, since "a text makes sense only to a reader who is capable of inferring meaningful relations" (Miššíková, 2012a, p.80). The appropriate use of cohesive means is undoubtedly important for building coherence relations within the text, in particular if the author intends to meet academic style conventions and obey the socalled scientific paradigm, which is related to "clarity, economy, rational argument supported by evidence, caution and restraint, and the incorporation of accepted theory through referencing and citation" (Bennett, 2009, p.52).

The adverbials called "conjuncts" represent one of four possible broad categories of grammatical function of adverbials, i.e. adjunct, subjunct, disjunct, and conjunct (Quirk et al., 1985, p.501). As the term suggests, "conjuncts" connect two linguistic units, which can be very large or very small, such as a constituent of a phrase realizing a single clause element, clause, sentence or paragraph, or a larger part of a text, by expressing a semantic relation. There are other frequently used terms for what are called "conjuncts" in this paper, for example, "linking adverbials" (Biber et al., 1999, p.761), "sentence adverbials" (Leech and Svartvik, 2002 , p.187) and "connective adjuncts" (Huddleston and Pullum, 2002, p.775), to name just a few. All these terms clearly emphasize the primarily connective function of this group of adverbials. 
The present study is based on Biber et al.'s semantic classification of linking adverbials (1999, pp.875-879), which comprises six semantic classes: 1) enumeration and addition; 2) summation; 3) apposition; 4) result/inference; 5) contrast/concession; and 6) transition. Accordingly, the adverbials analysed here are named as listing (enumerative and additive), summative, appositive, resultive/inferential, contrastive/concessive, and transitional.

As regards possible realization forms of linking adverbials, i.e. conjuncts (to use a one-word term in agreement with Quirk et al., 1985), these can be: 1) adverb phrases (including simple adverbs, e.g. firstly, then, finally, hence, and compound adverbs, e.g. moreover, however, nevertheless); 2) prepositional phrases (e.g. in addition, in other words, on the other hand); 3) finite clauses (e.g. what is more); or 4) non-finite clauses (e.g. to conclude, to summarize).

It should also be noted that conjuncts are always included in the subsequent part of the text and express a semantic relation to the previous, not necessarily adjacent part(s). This ordering of segments of text in a natural way entails placing a unit with known information first, i.e. before new information or some new aspect within it (cf. Firbas, 1992)

Conjuncts, viewed here as explicit guiding signals of semantic relations within a text, logically contribute to both cohesion and coherence. Since convincing argumentation and clear presentation of the author's views are of great importance in scholarly texts, conjuncts are assumed to be relatively frequent in all genres of academic discourse (Biber et al., 1999, p.880), including RAs. They are mostly used intentionally by the writer(s) to provide guidance to the readers through the text and help them arrive at an interpretation which is coherent with the author's communicative goals.

In order to meet the goals of the present study, the following research questions have been formulated:

1. Which semantic relations, such as apposition, contrast/concession, listing and result, tend to be expressed overtly by conjuncts in the genre of RAs?
2. Can conjuncts contribute to the interaction between the author(s) and reader(s) of a text and thus foster the interactive nature of written academic discourse?

3. Is there any cross-cultural variation in the use of conjuncts in RAs by Anglophone writers on the one hand and Czech and Slovak writers on the other?

4. Does the variation concern particular semantic classes of conjuncts or rather individual tokens chosen for the expression of particular semantic relations?

\section{Corpus and methodology}

This cross-cultural analysis is based on three specialized corpora, one representing Anglophone RAs written by experienced native speakers of English (amounting to 46,540 words), and two representing academic discourse by non-native speakers of English, notably Czech and Slovak writers (amounting to 46,595 and 23,559 words respectively). While the former corpus comprises six RAs written for the journal Applied Linguistics, the latter two corpora consist of ten RAs by Czech and seven by Slovak writers selected from the journal Discourse and Interaction. All RAs included in the analysis are single-authored articles published between 2008 and 2012 .

Let me now explain the differences in the number of RAs in each corpus. The basis for the study comprises ten RAs by Czech writers (with an average length of 4,659 words amounting to 46,595 words in the Czech speakers' corpus; CSC). These are compared to approximately the same number of words in RAs by Anglophone writers (with a much greater average length of 7,774 words, amounting to 46,540 words in the native speakers' corpus; NSC). In addition, in order to provide evidence of certain tendencies in the use of conjuncts that may not be present in the work of experienced writers from countries where Slavonic languages are spoken in comparison with Anglophone writers, a corpus of RAs by Slovak writers has been collected. Unfortunately, it has been possible to include only seven articles by Slovak writers from the period between 2008 and 2012 . These RAs form a relatively smaller 
corpus (with an average length of 3,365 words, amounting to 23,559 words in the Slovak speakers' corpus; SSC). Since the study takes into account normalized frequency rates per 1,000 words, it is assumed that the differences in the size of corpora do not distort overall tendencies in the use of conjuncts identified during the analysis.

In spite of certain limitations concerning the size, representativeness and generalizability of the findings, the abovedescribed specialized corpora are considered sufficient and more appropriate than large general corpora for a comparative study of written academic discourse, notably when exploring particular language means such as conjuncts in one genre. In order to obtain comparable data it has been necessary to exclude from the analysed material all parts of texts which comprise tables, figures, graphs, references, sources, examples and long quotations.

As for the methods applied, all texts were first processed with the help of the AntConc concordance programme, which is typically applied as a text analysis tool for processing corpus data. Nevertheless, it has also been necessary to examine the texts manually in order to achieve both qualitative and quantitative results because some of the language means under scrutiny can perform functions other than those of conjuncts.

\section{Comparison between non-native and native speakers of English}

In order to present a comprehensive picture of the types of conjuncts Czech and Slovak speakers of English apply in comparison with native speakers when writing their scholarly texts in English, this section provides results from the analysis of the individual semantic classes of conjuncts as found in the data. The examples selected for exemplification illustrate the role conjuncts perform in interaction between the author(s) and prospective reader(s) of a text and show which semantic classes can enable voices other than the author's to enter the text, thus enhancing the interactive nature of academic discourse and negotiation of meaning between discourse participants.

Before discussing the differences and similarities between the three corpora (i.e. native speakers' corpus = NSC; Czech speakers' corpus = CSC; and Slovak speakers' corpus = SSC) regarding the individual semantic classes, it must be noted that in order to provide comparable results for the use of conjuncts only normalized frequency rates have been used. As regards the data broken down in the following tables, some scarce and exceptional tokens of conjuncts have been excluded although they are taken into account in the total frequency rates per 1,000 words listed in the last lines of the tables. These concern cases where a particular type occurs once or twice in one of the three corpora only. Such conjuncts are mentioned only briefly in the comments accompanying every table, if relevant.

\subsection{Listing conjuncts}

Listing conjuncts can be further subdivided into enumerative (cf. Table 1a) and additive (cf. Table 1b). The former are used for enumeration of pieces of information in an order selected by the author, the latter to add pieces of information to one another. All writers in my data use listing conjuncts of both subgroups to arrange the information they intend to convey to prospective readers. Nevertheless, there are cross-cultural differences between Anglophone writers, who use both classes with almost identical frequency (0.54-0.56), and writers of Slavonic origin, who, apart from using listing conjuncts in general much more (1.70-1.95) than native speakers (1.10), apply conjuncts expressing enumeration slightly more than those introducing addition. It is therefore possible to identify a tendency in RAs by writers of Slavonic origin to order the information conveyed in a more explicit way. This is achieved by the use of enumerative conjuncts, such as first(ly), second(ly) and finally, as well as by additive conjuncts, such as furthermore and moreover, which are all more typical of non-native academic writing.

It should be noted here that the results concerning all conjuncts with normalized frequency higher than 0.1 tokens per 1,000 words are given in bold in all tables in Section 5 , so that the more common conjuncts are clearly recognizable. In addition, the types of conjuncts which are relatively frequent in all three corpora (with a frequency rate higher than 0.1 ) are written in bold (e.g. then in Table 1a). 


\begin{tabular}{|l|l|l|l|}
\hline Types of conjuncts & NSC & CSC & SSC \\
\hline finally & 0.02 & 0.26 & 0.21 \\
\hline first & 0.06 & 0.06 & 0.30 \\
\hline firstly & & 0.11 & 0.08 \\
\hline in the first place & & 0.06 & \\
\hline lastly & & 0.06 & \\
\hline next & & 0.02 & 0.04 \\
\hline second & 0.04 & 0.04 & 0.13 \\
\hline secondly & 0.03 & 0.11 & 0.08 \\
\hline then & 0.34 & 0.32 & 0.13 \\
\hline TOTAL & 0.54 & 1.09 & 0.98 \\
\hline
\end{tabular}

Table 1a: Listing (enumerative) conjuncts (frequency per 1,000 words)

\begin{tabular}{|l|l|l|l|}
\hline Types of conjuncts & NSC & CSC & SSC \\
\hline additionally & & & 0.13 \\
\hline also & 0.04 & 0.04 & 0.08 \\
\hline further & & 0.04 & 0.04 \\
\hline furthermore & 0.09 & 0.09 & 0.17 \\
\hline in addition & 0.16 & 0.09 & \\
\hline in particular & 0.04 & 0.09 & \\
\hline moreover & 0.02 & 0.32 & 0.17 \\
\hline similarly & 0.19 & 0.19 & 0.13 \\
\hline TOTAL & 0.56 & 0.86 & 0.72 \\
\hline
\end{tabular}

Table $1 \mathrm{~b}$ : Listing (additive) conjuncts (frequency per 1,000 words)

Tables $1 \mathrm{a}$ and $1 \mathrm{~b}$ provide evidence that listing conjuncts as a whole are more common in RAs by Czech and Slovak writers. Nevertheless, one conjunct - the enumerative then - is more frequently used by Anglophone writers (0.34). Although then tends to be rather informal, it is applied relatively often in comparison with all the other listing conjuncts. Its common use is probably connected with a slightly more informal style which usually characterizes native speakers' academic writing (cf. Chamonikolasová, 2005). Its frequency in the CSC (0.32), though, shows that Czech writers adopt this tendency, too (cf. Example 1). The enumerative then is the most common conjunct of all in the RAs by both Anglophone and Czech writers in my data. In the latter group, then is responsible for the majority of occurrences of listing conjuncts, together with the enumerative finally (0.26) and the additive moreover (0.32). The latter conjunct is shown in Example 2, which also comprises the additive further and the enumerative first. The other conjuncts in this example are discussed later. It should be noted that all conjuncts identified in all examples in Section 5 are underlined even when they occur in a text which primarily illustrates a different semantic role.

(1) CSC, Text 5

The recordings were played on the Plusdeck2c system and digitalized by means of the audio editor Audacity 1.2.6; they were then analyzed on an auditory basis with focus on (i) segmentation of the text into basic distributional fields, and (ii) intonation centre placement. Finally, the Czech speakers' versions were compared 
against the norm in such a way that an identical IC placement was judged as appropriate whereas a different placement (i.e. one not used by any of the native speakers) was either assessed as another possibility or inappropriate, depending on the interplay of all FSP factors. In ambiguous cases, regarding both tone unit boundaries and identification/assessment of nuclear accent, a consultation with one of the native speakers was arranged. The analyses were rechecked several weeks later to ensure the validity of the original assessment. The results of this comparative procedure (i.e. correspondences, deviations, etc.) were then tabularized (cf. Table 2).

(2) CSC, Text 9

In the following, the rules and features that hold for IRC openings in the corpus specified in light of a research question How do politeness/impoliteness strategies on Internet Relay Chat differ from those in a standard face-to-face conversation (model of Watts) and what counts as polite/impolite on IRC? are discussed.

First, it was observed that Schegloff's (1968) distribution rule and the notion of non-terminality of SA sequences do not function on IRC. It means that opening sequences can stand independently or in a changed order because of a high degree of disrupted adjacency, its incoherent and overlapping character. The data also show a high level of initiation attempts in contrast with further conversations. The only rule that can be applied in the IRC environment is Schegloff's terminating rule. Various opening techniques of individual participants are repeatable, however, not necessarily successful.

Further, it has been found that the least efficient type of opening is such an opening that does not carry any address, general or nickname. This mainly refers to vague openings, such as first contact questions. On the other hand, the analysis reveals that chat participants choose addressing by a general noun directly after AJS (100\%) rather than addressing directly by a nickname. The nickname is usually used after the initial greeting to all is made and a chat participant continues in conversation. It is assumed that addressing by a general noun right after AJS is regarded as being appropriate to the situation on IRC.

Moreover, it was found that on IRC in order to be successful in the ensuing discussion, a person does not only have to differentiate herself or himself from the others by the use of capital letters, or by the use of language, such as to choose an unusual style, but also has to address other participants individually.

Examples 1 and 2 provide evidence that both classes of listing conjuncts are often applied by writers of Slavonic origin in particular in order to enable the reader(s) to follow a path through a text full of information, thus helping them interpret the text as a coherent piece of discourse which is in agreement with the scientific paradigm mentioned above.

\subsection{Summative conjuncts}

Conjuncts which indicate that what follows serves as a summary or conclusion of the information in the preceding part(s) of the text are not much represented in any of the three corpora, having the frequency of 0.06 0.21 tokens per 1,000 words only. The most typical summative conjunct, overall, is shown in Example 3. It illustrates the author's intention to summarize what has been stated before, thus helping the reader(s) understand the rules described. Among conjuncts of this group it is possible to find the only one realized by a non-finite infinitive clause that has more than one occurrence in my data (i.e. to conclude). 


\begin{tabular}{|c|c|c|c|}
\hline Types of conjuncts & NSC & CSC & SSC \\
\hline overall & 0.02 & 0.02 & 0.08 \\
\hline taken together & 0.06 & & \\
\hline to conclude & & 0.02 & 0.04 \\
\hline TOTAL & 0.11 & 0.06 & 0.21 \\
\hline
\end{tabular}

\section{Table 2: Summative conjuncts (frequency per 1,000 words)}

\section{(3) SSC, Text 1}

In the given extract both participants are engaged in a struggle for access to discursive resources employed in the control over floor and content whereby they discursively negotiate the lines of participation and (re)construct the discourse format of the show. The host, with whom the institutional power is invested, appears to have a monopoly over the floor, by utilizing interruption as a principal control device and reinforcing it by an extensive (and effective) use of reduplication of linguistic structures, as well as over the content, by employing the strategy of formulation of caller's assumed claims. The caller, being almost always on the defensive, avails himself of the resources of interruption and repair. Overall, in the conflictual situations participants employ little facework to signal willingness to attend to coparticipants' face-needs. Since it is probably the case that this kind of behaviour constitutes a part of their habitus for the talk-show, they may have stayed within the framework of politic behaviour; there are clues, however (such as the caller's invocation of the TT rule), that partners' behaviour may have been taken as falling out of line and, being thus negatively marked, it may have become open to interpretation as impolite.

Example 3, taken from the SSC, testifies that even when providing a summary many authors cannot avoid expressing contrasts and consequences, introduced above all by however and thus, which are included among "a few single adverbs commonly [used]" (Biber et al., 1999, p.885) in all academic discourse written by native speakers of English and, as my results show, also by Czech and Slovak writers. The verbalization of different opinions and attitudes in scholarly text clearly enhances the interaction between the author and prospective reader(s) of the text.

\subsection{Appositive conjuncts}

The results in Table 3 indicate that conjuncts expressing apposition are more typical of the RAs by writers of Slavonic origin (amounting to 4.24-4.49 tokens per 1,000 words) than those by Anglophone writers (reaching 2.51 tokens). This variation can be explained by the fact that Czech and Slovak scholars, although experienced in their respective research fields, often consider it more important to enhance their scientific credibility within the academic discourse community by providing prospective reader(s) with explanations and evidence. These exemplifications, reformulations and restatements foster the negotiation of meaning between discourse participants and help the reader(s) interpret the text as coherent and in agreement with the author's intentions.

Appositive conjuncts applied to introduce exemplification comprise e.g., for example and for instance, the first two being relatively frequent in all three corpora (1.14-1.49 and 0.49-0.55 respectively). Those used for reformulation are represented above all by i.e., in other words and namely, all three being most common in the RAs by Czech writers, who in general use appositive conjuncts most frequently (4.49) of all writers included in the study. 


\begin{tabular}{|c|c|c|c|}
\hline Types of conjuncts & NSC & CSC & SSC \\
\hline e.g. & 1.35 & 1.14 & 1.49 \\
\hline for example & 0.51 & 0.49 & 0.55 \\
\hline for instance & 0.21 & 0.15 & 0.17 \\
\hline i.e. & 0.11 & 1.85 & 1.10 \\
\hline in other words & 0.04 & 0.19 & 0.13 \\
\hline more specifically & 0.02 & 0.06 & 0.08 \\
\hline namely & 0.04 & 0.47 & 0.08 \\
\hline specifically & 0.06 & 0.02 & 0.04 \\
\hline that is & 0.15 & 0.09 & 0.04 \\
\hline TOTAL & 2.51 & 4.49 & 4.24 \\
\hline
\end{tabular}

\section{Table 3: Appositive conjuncts (frequency per 1,000 words)}

Conjuncts introducing an exemplification signal that the information provided is in some sense included in the previous part(s) of the text and the receiver of the message should assume that there may be other alternatives besides the one already mentioned. The three conjuncts used for exemplification have similar frequencies in all three corpora. Owing to only minor variation in their use, it can be stated that it depends on individual authors' stylistic preferences rather than cross-cultural differences which of these conjuncts (e.g., for example and for instance) they choose, as in Example 4, where the author resorts to for example and e.g. This example illustrates an interesting way of introducing other scholars' voices in a text, namely by exemplifying and referring to similar or different standpoints expressed by others working in the same field, a strategy which clearly enhances the interactive nature of academic discourse.

\section{(4) NSC, Text 5}

These impressive studies are very good at explaining the initial stages of the development of a lexicon in a group of interacting agents, but they have very little to say about the development of large, bilingual lexicons. Their most important limitation is that Steels' work deals only with very small word sets. In his 1997 paper, for example, the target vocabulary acquired by the agents is a mere ten words. Steels argues strongly that these existence proofs should scale up to much large lexicons, but he does not actually show that this is the case. More interestingly, perhaps, the lexicons acquired by Steels agents do not really illustrate the one critical feature of largescale human lexicons. His lexicons are essentially a list of words and meanings, rather than networked structures of the kind described by Aitchison (1987) for example. A similar approach to emergence in a lexicon is to be found in the work of Zuidema and Westermann (e.g. 2001, 2003). Like Steels, Zuidema and Westermann work with agents which interact with each other in a series of language games, but they use these games to examine what features of a lexicon make it easy or difficult for the agents to learn. They conclude that a number of emergent features are characteristic of an optimal lexicon. Optimal lexicons exhibit specificity, every meaning in the lexicon is associated with a single form that expresses it, and every form in the lexicon has exactly one interpretation. Optimal lexicons also exhibit distinctiveness, that is the forms they include are easily distinguishable and maximally dissimilar.

Apart from appositive conjuncts used for exemplification, Example 4 includes one token of that is, a conjunct which is most frequent among those used for reformulation by Anglophone writers. It is slightly more frequent $(0.15)$ than the abbreviated form i.e. (0.11). By comparison, that is is less common in RAs by non-Anglophone writers (0.040.09 ), who give preference to the abbreviated 
form i.e, which represents the most typical conjunct of all used for reformulation in RAs by Czech (1.85) and Slovak (1.10) writers (cf. Example 6).

The conjuncts for instance and for example are mutually interchangeable; however, as the results in Table 3 reveal, the former is much less common, having half the frequency of the latter, and, as Biber et al. (1999, p. 890) maintain, the use of for instance "appears more a matter of author style". The appositive for instance can also be used successfully to introduce other voices in a text, as in Example 5, which confirms my assumption that appositive conjuncts such as e.g., for example and for instance can contribute to the interaction between the author and others working in the same field.

(5) NSC, Text 2

Sexually selected characteristics (e.g. large horns or elaborate plumage) are often found in males, and this reflects the fact that in many species it is males who do the courting while the role of females is to choose among potential mates. Peacocks, for instance, engage in lekking, ritually displaying themselves in areas frequented by peahens. Some scholars think that language fulfils analogous functions among humans. Geoffrey Miller (1999, 2000), for instance, argues that human languages are much more elaborate than they need to be to serve purely communicative purposes. This can be explained by hypothesizing that speaking served the purpose of displaying the (male) speaker's reproductive fitness.

Conjuncts expressing reformulation, which are represented in Example 6 by i.e., namely and in other words, signal that the second unit is to be regarded as "a restatement of the first, reformulating the information it expresses in some way or stating it in more explicit terms" (Biber et al., 1999 , p.876). The findings that these conjuncts tend to be most common in the RAs by Czech writers further testify my assumption that non-Anglophone writers consider it important to provide prospective reader(s) with reformulations and restatements in order to support their argumentation and thus scientific credibility. This tendency is also visible, though less prominent, in the results drawn from the RAs by Slovak writers (cf. i.e. with the frequency of 1.10 in Table 3).

\section{(6) CSC, Text 1}

The domain of the theory of functional sentence perspective (FSP) has been explored mostly at the sentential level, i.e. in the area of the basic distributional field created by the clause. Recently, however, attention has also been paid to the functional picture of higher hierarchical levels of text. This research has shown that an FSP analysis of a distributional macrofield is a promising step in the study of FSP and that it can reveal significant characteristic features of a whole text (cf. Adam 2004, 2006, Pípalová 2005, Firbas 1995, Svoboda 1996).

The present paper attempts to trace the theme-rheme structure (as described on the clausal level) at the textual level, namely that of scripted sermons. In other words, the whole distributional macrofield of a sermon will be examined from the point of view of its functional perspective. For a thorough treatment of the theory of FSP, the reader is referred to Firbas (1992).

\subsection{Resultive/inferential conjuncts}

The primary role of resultive/inferential conjuncts (Table 4) is to signify that what follows states the result or consequence of what precedes, thus enhancing the readers' interpretation in agreement with the author's intentions and establishing coherence. Conjuncts of this group are distributed rather unevenly, some of them having a frequency rate of one or two tokens in one or two of the three corpora (0.01-0.02), while others amount to a normalized frequency rate of almost 1.00, as is the case of thus, which is the most typical resultive conjunct in the RAs by non-native speakers of English, amounting to 0.97 and 0.72 tokens in the CSC and SSC respectively. 


\begin{tabular}{|c|c|c|c|}
\hline Types of conjuncts & NSC & CSC & SSC \\
\hline (and) so & 0.26 & 0.04 & 0.04 \\
\hline accordingly & 0.04 & & 0.13 \\
\hline as a result & & 0.02 & 0.17 \\
\hline consequently & 0.09 & 0.06 & 0.08 \\
\hline for this reason & & 0.02 & 0.13 \\
\hline hence & 0.06 & 0.06 & 0.55 \\
\hline in this case & 0.04 & 0.11 & 0.08 \\
\hline in this respect & 0.04 & 0.04 & 0.08 \\
\hline in this way & 0.06 & 0.02 & 0.04 \\
\hline of course & 0.06 & & \\
\hline so that & 0.11 & 0.04 & \\
\hline then & 0.54 & 0.28 & 0.25 \\
\hline therefore & 0.28 & 0.86 & 0.13 \\
\hline thus & 0.32 & 0.97 & 0.72 \\
\hline TOTAL & 1.91 & 2.64 & 2.42 \\
\hline
\end{tabular}

Table 4: Resultive/inferential conjuncts (frequency per 1,000 words)

Two conjuncts, namely therefore and thus, represent more than one third of all resultive conjuncts found in the RAs by Anglophone (0.60) and Slovak (0.85) writers and more than two thirds in those by Czech writers (1.83) in my data. It is worth noting that therefore and thus, along with however and for example, have been found in Biber et al. (1999, p.885) to be the most typical conjuncts in all academic texts written by native speakers of English. Three of these conjuncts are shown in the following example, written by a Czech. The example comprises two tokens of the appositive for example and illustrates how conjuncts of this category (cf. the second token of for example) can easily introduce a voice other than the author's own in the text.

(7) CSC, Text 5

As it follows from the above mentioned, the originator or producer of newspaper discourse cannot be viewed as an individual; therefore, we can hardly speak of the sender and his or her intentions, which we would normally consider in spoken interaction, for example. In our view, it is not possible to compare the communication that takes place in newspaper discourse between the writer and reader, as we would analyze it in faceto-face conversation because with newspaper discourse the negotiation of meaning is excluded (for negotiation of meaning in face-to-face conversation, of. Povolná 2009). The traditional sender/receiver model is thus insufficient for news discourse analysis and, as Scollon (1998) suggests, should be abandoned. The terms writer and reader need to be understood as general concepts, which do not denote particular individuals.

On the other hand, with so many national and local newspapers in the market, it is a matter of survival for newspapers that they identify their readership in order to be successful businesses. Without a considerable number of readers a newspaper cannot compete with other newspapers and other types of modern media. Scollon (1998), for example, not only refutes the sender/receiver model but also claims that it is virtually impossible to define the so-called implied reader.

The relatively frequent use of then (0.54) and so (0.26) in the RAs by Anglophone writers is not surprising since these conjuncts are considered rather informal and typical in particular of conversation (Biber et al., 1999, 
p.886); their application in my data gives further evidence of a more informal and dialogic way of expression typically associated with academic texts written by native speakers of English. Although these two conjuncts also occur in the RAs by Czech and Slovak writers, they are less common, then having the frequency of 0.25-0.28 and so only 0.04 . This may be caused by nonnative speakers' awareness of their rather informal stylistic value. The resultive then used in a correlative pair with if is shown in Example 8, which also comprises one token of the additive furthermore.

(8) NSC, Text 2

There is an obvious tension between this account and the orthodox wisdom which holds that women are the more talkative and verbally skilful sex. If the courtship story is correct, then men would logically have had more to gain than women from traits like loquacity, articulacy and fluency. Furthermore, on the principle that modern humans inherit the genes of the most successful reproducers among their ancestors, this male verbal advantage should still be observable.

As regards the resultive hence, it is worth noting that this rather formal conjunct is not much represented in my data, having the frequency of 0.06 both in the NSC and CSC; this is in accordance with Biber et al. (1999, p.887), who maintain that hence is used only in one fifth of all academic texts. However, it appears relatively frequently in the RAs by Slovak writers in my data, where it represents the second most common resultive conjunct (0.55). One token is shown in Example 9, which is taken from an RA comprising the highest number of cases in which hence is used, thus being responsible for its relatively high frequency in the SSC. It can now be concluded that it is a matter of particular writers' stylistic preferences rather than cross-cultural variation whether they resort to the most common resultive conjuncts thus and therefore, the slightly informal then or the rather more formal hence.

\section{(9) SSC, Text 10}

The other observation in the left-hand panel of Figure 2 is that females have shorter latencies than males; $F(1,3919)=$ 15.96, $p<0.001$. Hence, the latency measure points to a more active and dominant role of females in our data. Finally, there was no significant correlation between a speaker's gender and his/her role in conversation on turn latency.

Next we looked at the relationship between the gender of the speaker who starts a turn and the gender of his/her interlocutor, as a function of turn latency. This is illustrated in the right-hand panel of Figure 2. We see that in addition to the main effect of speaker gender mentioned above, the gender of the listener does not significantly affect speaker latency; $F$ ( 1 , 3919) $=0.256, p=0.62$. However, the gender of interlocutors does play a role in the degree of overlap, as seen in the significant interaction between the two factors; $F(1,3917)=6.56, p=0.01$. Hence, the difference between the latencies of males and females is much greater in the presence of a female interlocutor than a male one. Put in a different way, the conversation tends to be more overlapped for female speakers, especially if both the speaker and the interlocutor are female, and the flow is less overlapped if a male talks to a female.

So far, we have looked at latency in all turns irrespective of the turn type. Now we will explore the realization of dominance and the role in conversations through the turn-type.

Example 9 is a model illustration of the author's guidance for the prospective reader(s) through a relatively complicated text full of demanding information. To organize the text, the author resorts to different semantic classes of conjuncts: apart from two occurrences of the resultive hence, the author also uses the enumerative finally and next and even the transitional now, which is discussed in Section 5.6.

\subsection{Contrastive/concessive conjuncts}

My results concerning contrastive/concessive conjuncts are broken down in Table 5 . The 
total frequency rates in all three corpora are rather similar, ranging from 2.67 to 2.96 tokens per 1,000 words. By marking contrastive or concessive relations between information provided in different, not necessarily adjacent, parts of the text conjuncts of this semantic role naturally contribute to the interactive nature of academic discourse (cf. Malá, 2006; Povolná, 2010) and enable voices other than the author's to enter the text (cf. Example 10). The contrastive conjuncts analysed here subsume those expressing contrast as well as concession, since concession is viewed as a special case of contrast, notably that between the expected causal relationship and the actual situation (cf. Dušková et al., 1988). In addition, treating contrastive and concessive conjuncts as one group is supported by Biber et al.'s statement that "in some cases, elements of contrast and concession are combined in uses of linking adverbials" (1999, pp.878-979), which the examples provided below testify.

\begin{tabular}{|c|c|c|c|}
\hline Types of conjuncts & NSC & CSC & SSC \\
\hline actually & 0.02 & & 0.04 \\
\hline after all & 0.02 & 0.02 & \\
\hline albeit & 0.02 & 0.04 & \\
\hline at the same time & 0.17 & 0.02 & \\
\hline by contrast & 0.09 & & \\
\hline conversely & 0.02 & 0.13 & 0.08 \\
\hline however & 1.37 & 1.63 & 1.57 \\
\hline in contrast & & 0.04 & 0.04 \\
\hline instead & 0.13 & & \\
\hline nevertheless & 0.13 & 0.15 & 0.08 \\
\hline nonetheless & 0.04 & 0.02 & \\
\hline of course & 0.09 & 0.04 & \\
\hline on the contrary & 0.02 & 0.04 & \\
\hline on the other hand & 0.09 & 0.19 & 0.17 \\
\hline or else & 0.02 & 0.04 & \\
\hline rather & 0.17 & 0.02 & 0.13 \\
\hline still & 0.15 & 0.19 & \\
\hline though & 0.02 & 0.04 & \\
\hline yet & 0.24 & 0.13 & 0.42 \\
\hline TOTAL & 2.96 & 2.79 & 2.67 \\
\hline
\end{tabular}

\section{Table 5: Contrastive/concessive conjuncts (frequency per 1,000 words)}

The contrastive however achieves the highest frequency not only of all contrastive conjuncts but also of all conjuncts in all three corpora in my study, amounting to $1.37,1.63$ and 1.57 tokens per 1,000 words in the RAs by native, Czech and Slovak speakers of English respectively. There are only two exceptions, namely among appositive conjuncts, where i.e. amounts to 1.85 in the CSC and e.g. 1.49 in the SSC. Both the contrastive however and the appositive i.e. are shown twice in Example 10, which is taken from the RAs by Czech writers, who apply these two conjuncts most frequently. The example also illustrates how contrasting ideas can be introduced in an academic text 
owing to the application of conjuncts (cf. as a result, in contrast and however). It must be admitted, however, that apart from conjuncts there are other language means that enable the expression of contrast/concession and reference to other scholars' voices in the text, such as conjunctions (cf. despite the fact that at the beginning of Example 10) and prepositional constructions (cf. despite in Example 12 below); the study of these is beyond the scope of this article, however. (For some culture-specific aspects when solving conflicts and/or communicating (dis)agreements in academic discourse, see Miššíková, 2012b.)

(10) CSC, Text 4

Despite the fact that the results of the analysis fully support Hoey's concept about the organisation of the text through lexical cohesion we are aware of the fact that Hoey manifested his theory on philosophical texts that represent a genre disparate mainly from economic texts in the data. The specifics of economic texts lie in their interconnection with instrumental devices such as equations, graphs, charts, tables and statistics, i.e. textual units with metadiscursive labelling function. Most equations are accompanied by explanatory sections where various subscripts and indexes are explained. As a result, the parts containing most equations are the least cohesive. In contrast, the most cohesive parts are the introductory sections, since these concisely and lucidly outline the RAs' content. Most problematic seem to be theoreticallybiased chapters 1 and 2, which present theoretical background and feedback for one's own research. However, this disproportion is fully compensated for in the texts through the introductory section and then by those conclusive chapters 3-5. This confirms and reflects carefully planned and organised layout of RAs. One more important point arises when considering how demanding and laborious a task it is to construct such a summary since there are some computer tools such as an electronic-like resource WordNet, SummariserPort and other summarygenerating systems based on lexical cohesion. However, these tools are able to represent a computer implementation only of the first two of Hoey's four categories of lexical patterning, i.e. simple and complex repetition.

Conjuncts expressing contrast/concession tend to be frequently applied not only in my data (2.67-2.96) but in all written academic discourse, since they express relations that are, according to Kortmann (1991, p.161), regarded as "the most complex of all semantic relations that may hold between parts of a discourse". Thus it is not surprising that they tend to be expressed overtly by conjuncts in the case of this study, for example (cf. Wagner, 2011; Povolná, 2012; Vogel; 2013).

In addition to however, other conjuncts typically used for contrast/concession are yet, still and nevertheless. Yet is the second most typical conjunct in the RAs by Slovak writers (0.42). It is shown, together with however, in the example that follows:

(11) SCC, Text 2

Based on anecdotal evidence, the Japanese are perceived to be hard-working, always polite and respectful, and seem to be rather embarrassed and shy; they look very serious so one never knows what they think; their attitude to foreigners is, however, friendly. Australians at all times seem to be easy-going and laid-back, also generous and polite; they are very sporty and big beer-lovers; they are friendly and tolerant to foreigners. The British seem to be reserved, self-centered and fussy, which is why others may see them as arrogant; in their own community they are very polite and gentlemanly, yet their attitude to foreigners might be conceived of as superior.

Example 12, written by an Anglophone writer, comprises several tokens of different types of conjuncts. In addition to the contrastive nevertheless, there are several tokens of conjuncts representing other semantic classes, namely the appositive for example, the additive in addition and the resultive so. Moreover, this example starts with the prepositional construction despite the similarities ..., which illustrates the abovementioned possibility of expressing 
semantic relations between parts of the text with means other than conjuncts.

\section{(12) NSC, Text 1}

Despite the similarities in themes, each interview is a record of a specific social interaction, and each interviewee interprets this in his or her own way. Interviewees inevitably make judgements about the interviewer and her expectations, including about how far she shares their knowledge about the things they reference. For example, interviewees who are much older than their interlocutor, or who have lived in places beyond Birmingham, tend to assume that some of their experiences will be unfamiliar to the interviewer, and so they explain them in greater detail. In addition, these interviews cannot be neutral descriptions, or representations, of each self and its history, as they are interactional tellings, produced in a context of interpretation and negotiation (Wortham 2000; Pavlenko 2007). Nevertheless, there is sufficient homogeneity about the interviews for them to have certain features in common, including linguistic features.

\subsection{Transitional conjuncts}

Conjuncts expressing transition, which can be further subdivided into discoursal and temporal, are not much represented in my data, which is in agreement with Biber et al.'s findings that "transition adverbials are rare in all registers" (1999, p.880). Both subgroups mark the insertion of information that does not follow directly from the previous text. Although Quirk et al. (1985, p.636) consider the discoursal now to be rather informal, the tokens found in the data prove that in spite of its assumed informality it can appear even in the formal genre of RAs, as in the example that follows:

\section{(13) CSC, Text 2}

Turning now to the quantitative aspect, all in all, the overall research corpus includes 2,070 paragraphs of contemporary British English. It is made up of three register corpora, each comprising 690 paragraphs. Every register corpus is in turn composed of two subcorpora, each featuring 345 paragraphs. Every register subcorpus includes three source subcorpora. Finally, the share of the sources is even, as each source embraces 115 continuous graphic paragraphs. The list of the corpus sources (all published within the last two decades), together with their abbreviations, is provided in the Primary Sources at the end of the paper.

\begin{tabular}{|c|c|c|c|}
\hline Types of conjuncts & NSC & CSC & SSC \\
\hline now & 0.09 & 0.17 & 0.04 \\
\hline TOTAL & 0.15 & 0.17 & 0.04 \\
\hline
\end{tabular}

Table 6: Transitional conjuncts

Example 13 also includes two tokens of conjuncts of other semantic classes, namely the summative all in all, with only one occurrence in my data, and the listing finally, which is more characteristic of non-native speakers' academic texts. As is evident from Table 6, the discoursal now is the only type of transitional conjunct identified in the RAs by Czech (cf. Example 13) and Slovak writers (cf. Example 9 above). The other transitional conjuncts, which are not explicitly listed in Table 6, include initially, meanwhile and subsequently. These occur exceptionally, each having only one occurrence in the RAs by native speakers.

\section{Conclusions}

The overall frequency rates of all conjuncts under scrutiny are given in Table 7 . It provides evidence that writers of Slavonic origin, both Czech and Slovak, apply conjuncts as overt guiding signals of the relations between parts of a text to a much higher extent (12.10 and 10.74 respectively) than Anglophone writers (8.72) (for similar tendencies in the use of metadiscursive 
elements in academic discourse produced by non-native in comparison with native speakers of English, see Mauranen 2012). The most noticeable variation concerns the extent to which certain semantic classes are applied: listing, resultive and in particular appositive conjuncts are used by both Czech and Slovak writers with a frequency of occurrence much higher than that of native speakers.

\begin{tabular}{|c|c|c|c|c|c|c|}
\hline Type of corpus & 46,540 & NSC & $\begin{array}{c}46,59 \\
5\end{array}$ & CSC & 23,559 & SSC \\
\hline Semantic role & No. & Norm. freq. & No. & Norm. freq. & No. & Norm. freq. \\
\hline Listing & 51 & 1.10 & 91 & 1.95 & 40 & 1.70 \\
\hline Summative & 5 & 0.11 & 3 & 0.06 & 5 & 0.21 \\
\hline Appositive & 117 & 2.51 & 209 & 4.49 & 87 & 4.24 \\
\hline Resultive/inferential & 89 & 1.91 & 123 & 2.64 & 57 & 2.42 \\
\hline $\begin{array}{c}\text { Contrastive/concessiv } \\
\text { e }\end{array}$ & 138 & 2.96 & 130 & 2.79 & 63 & 2.67 \\
\hline Transitional & 7 & 0.15 & 8 & 0.17 & 1 & 0.04 \\
\hline Total & 407 & 8.72 & 564 & 12.10 & 253 & 10.74 \\
\hline
\end{tabular}

\section{Table 7: Frequency rates of all semantic classes of conjuncts in all three corpora}

Drawing on the results exemplified and discussed above, the following answers can be suggested to the research questions formulated in Section 3 above:

1) Which semantic relations, such as apposition, contrast/concession, listing and result, tend to be expressed overtly by conjuncts in the genre of RAs?

Conjuncts as important cohesive means are applied in all three corpora to express all possible semantic relations that may hold between parts of a text. Nevertheless, Slavonic writers, both Czech and Slovak, consider it of greater importance to apply conjuncts for the overt expression of certain semantic relations, in particular those of listing, apposition, and result/inference. These relations are expressed by conjuncts (as well as other means not studied here) to provide safe guidance to the prospective reader(s) through a text which is full of often quantitative information, to support the author's argumentation by evidence and exemplifications, or to convey the results and consequences of one's research findings to the academic audience. Thus, it can be stated that conjuncts clearly contribute to the establishment of the author's scientific credibility within the academic community. This predilection is in accordance with the scientific paradigm mentioned in Section 3 above, which, as my results prove, is still an important aspect of RAs written in English as an additional language by Czech and Slovak authors.

2) Can conjuncts contribute to the interaction between the author(s) and reader(s) of a text and thus foster the interactive nature of written academic discourse?

Based on my findings, it can be assumed that conjuncts can contribute to the interaction between the author(s) and reader(s) of a text, which is particularly evident with semantic relations often considered most informative and thus most important of all, i.e. contrast/concession and result/inference (Kortmann, 1991), both frequently expressed in all the RAs analysed in this study.

3) Is there any cross-cultural variation in the use of conjuncts in RAs by Anglophone writers on the one hand and Czech and Slovak writers on the other?

There are only minor cross-cultural distinctions between the ways writers of Slavonic origin and Anglophone writers use conjuncts, notably in the choice of the most frequent types within each semantic class. This can result from differences in particular 
writers' styles (e.g. a preference for the use of e.g. and for example rather than for instance, i.e. rather than that is, or thus rather than therefore), topics discussed (e.g. some requiring frequent exemplification and thus appositive conjuncts such as i.e. and namely) and above all individual writers' preferences, which can be influenced by writing conventions transferred from the authors' mother tongues (e.g. the use of in other words or on the other hand, probably under the influence of similar phrases in Czech and Slovak). The conjuncts considered most typical of all academic discourse, i.e. however, thus, therefore and for example (Biber et al., 1999), are commonly used in all three corpora. In addition, both Czech and Slovak writers frequently resort to conjuncts expressing listing (finally, first(ly) and moreover) and apposition (i.e., e.g. and namely), and Anglophone writers use the resultive so and then, which are both considered slightly informal.

4) Does the variation concern particular semantic classes of conjuncts or rather individual tokens chosen for the expression of particular semantic relations?

In the case of semantic relations which are expressed with similar frequencies in all three corpora, variation tends to concern the individual tokens applied by particular writers from different academic communities and seems to be associated with particular writers' stylistic preferences. By comparison, when greater variation appears, such as that in the expression of listing and apposition, the variation concerns both semantic classes as wholes and particular types of conjuncts.

The expectation that academic texts written by Anglophone writers are more interactive, thus comprising more conjuncts, has not been verified. As testified by my findings, Czech and Slovak writers attempt to adopt the academic style conventions typical of the dominant Anglophone discourse community, such as linear organization of text through clear division into paragraphs and sections and application of overt guiding signals on form and content which, quite naturally, comprise an appropriate use of text-organizing means, including conjuncts. The adoption of Anglophone style conventions by non-native speakers of English can be caused not only by instructions provided in academic writing style manuals (Bennett, 2009) and university courses, but also by the fact that Slavonic writers attempt to adopt and use "model" academic English and therefore seem to suppress intentionally any culture-specific aspects when writing scholarly texts in English.

Despite certain limitations in the size and representativeness of the data analysed, it is hoped that this small-scale research has revealed some interesting current tendencies in the writing of RAs by authors from two small discourse communities in Central Europe - the Czech Republic and Slovakia. However, only further research, which should comprise more data from other countries where Slavonic languages are spoken and perhaps also other genres of academic discourse, can confirm the conclusions suggested above.

\section{References}

BAKHTIN, M.M., 1986. Speech genres and other late essays. Austin, Texas: University of Texas Press.

BAZERMAN, C., 2004. Intertextuality: How texts rely on other texts. In: C. Bazerman and P. Prior, eds. What writing does and how it does it: An introduction to analyzing texts and textual practices. Mahwah, New Jersey: Lawrence Erlbaum Associates, Inc., Publishers. pp. 83-96.

BENNETT, K., 2009. English academic style manuals: A survey. Journal of English for Academic Purposes, vol. 8, no. 1, pp. 43-54.

BENNETT, K., 2010. Academic discourse in Portugal: A whole different ballgame? Journal of English for Academic Purposes, vol. 9, no. 1, pp. 21-32.

BENNETT, K., 2015. Towards an epistemological monoculture: Mechanisms of epistemicide in European research publication. In: R. Pló Alastrué and C. Pérez-Llantada, eds. English as a scientific and research language. Debates and discourses. English in Europe, vol. 2, Language and social Life. Berlin and New York: Mouton de Gruyter. 
BIBER, D., JOHANSSON, S., LEECH, G., CONRAD, S. and FINEGAN, E., 1999. Longman grammar of spoken and written English. London: Longman.

CHAMONIKOLASOVÁ, J., 2005. Comparing the structures of academic texts written in English and Czech. In: M. Huttová, ed. Slovak studies in English 1. Bratislava: Comenius University, pp. 77-84. ČMEJRKOVÁ, S. and DANEŠ, F., 1997. Academic writing and cultural identity: The case of Czech academic writing. In: A. Duszak, ed. Culture and styles of academic discourse. Berlin and New York: Mouton de Gruyter. pp. 40-62.

DONTCHEVA-NAVRATILOVA, O., 2007. On coherence in written discourse. In: J. Schmied, C. Haase and R. Povolná, eds. Complexity and coherence. Approaches to linguistics research and language teaching. REAL Studies 3. Göttingen: Cuvillier Verlag, pp. 127-145.

DONTCHEVA-NAVRATILOVA, O., 2012. Cross-cultural differences in the construal of authorial voice in the genre of diploma theses. In: C. Berkenkotter, V.K. Bhatia and M. Gotti, eds. Insights into academic genres. Linguistic insights. Studies in language and communication. vol. 160. Bern: Petr Lang, pp. 301-328.

DONTCHEVA-NAVRATILOVA, O., 2012. Coherence and persuasion in political speeches: Ideological coherence in coherent discourse. In: O. Dontcheva-Navratilova, R. Jančaříková, G. Miššíková and R. Povolná, eds. Coherence and cohesion in English discourse. Brno: Masaryk University, pp. 129-153. DUSZAK, A., 1997. Cross-cultural academic communication: A discourse-community view. In: A. Duszak, ed. Culture and styles of academic discourse. Berlin and New York: Mouton de Gruyter, pp. 11-39.

DUŠKOVÁ, L., STRNADOVÁ, Z., KNITTLOVÁ, D., PEPRNÍK, J. and TÁRNYIKOVÁ, J., 1988. Mluvnice současné angličtiny na pozadí češtiny. Prague: Academia.

FAIRCLOUGH, N., 1995. Critical discourse analysis. London: Longman.

FIRBAS, J., 1992. Functional sentence perspective in written and spoken communication.

Cambridge: Cambridge University Press.

FOWLER, R., 1986. Linguistic criticism. Oxford: Oxford University Press.

HABERLANDT, K., 1982. Reader expectations in text comprehension. In: J.-F. Le Ny and W. Kintsch, eds. Language and comprehension. Amsterdam: North-Holland, pp. 239-249.

HALLIDAY, M.A.K. and HASAN, R., 1976. Cohesion in English. London and New York: Longman. HEDGCOCK, J.S., 2005. Taking stock of research and pedagogy in L2 writing. In: E. Hinkel, ed. Handbook of research in second language teaching and learning. Mahwah and London: Lawrence Erlbaum, pp. 597-613.

HOEY, M., 2001. Textual interaction. An introduction to written discourse analysis. London and New York: Routledge.

HUDDLESTON, R. and PULLUM, G.K., 2002. The Cambridge grammar of the English language. Cambridge: Cambridge University Press.

HYLAND, K., 2004. Genre and second language writing. Ann Harbor: The University of Michigan Press.

HYLAND, K., 2005. Metadiscourse. London and New York: Continuum.

KORTMANN, B., 1991. Free adjuncts and absolutes in English. London: Routledge.

LEECH, G. and SVARTVIK, J., 2002. A Communicative grammar of English. $2^{\text {nd }}$ ed. London: Longman. MALÁ, M., 2006. Contrastive markers and dialogicality. In: R. Povolná and O. Dontcheva-

Navratilova, eds. Discourse and interaction 2. Brno: Masaryk University, pp. 97-107.

MAURANEN, A., 1993. Contrastive ESP rhetoric: Metatext in Finnish-English economics texts.

English for Specific Purposes, vol. 12, no. 1, pp. 3-22.

MAURANEN, A., 2012. Exploring ELF. Academic English shaped by non-native speakers. Cambridge: Cambridge University Press.

MAURANEN, A., HYNNINEN, N. and RANTA, E., 2010. English as an academic lingua franca: The ELFA project. English for Specific Purposes, vol. 29, no. 3, pp. 183-190.

MIŠŠíKOVÁ, G., 2012 a. Coherence in literary discoure. In: O. Dontcheva-Navratilova, R. Jančaříková, G. Miššíková and R. Povolná. Coherence and cohesion in English discourse. Brno: Masaryk University, pp. 79-102.

MIŠŠ́́KOVÁ, G., 2012b. Politeness strategies in academic digital discourse. Discourse and Interaction, vol. 5 no. 1, pp. 49-62. 
MUR-DUEŇAS, P., 2008. Analysing engagement markers cross-culturally: The case of English and Spanish business management research articles. In: S. Burgess and P. Martín-Martín, eds. English as an additional language in research publication and communication. Linguistic insights. Studies in language and communication. vol. 61. Bern: Peter Lang, pp. 197-213. PÉREZ-LLANTADA, C., 2011 . Constructing the ideal readership: Heteroglossic (dis)engagement in research writing practices across cultures. In: V. K. Bhatia, P. Hernández and P. Pérez-Paredes, eds. Researching specialised languages. Studies in corpus linguistics. Amsterdam: John Benjamins, pp. 25-45.

POVOLNÁ, R., 2009. Exploring interactive discourse markers in academic spoken discourse. In: O. Dontcheva-Navratilova and R. Povolná, eds. Coherence and cohesion in spoken and written

discourse. Newcastle upon Tyne: Cambridge Scholars Publishing, pp. 60-80.

POVOLNÁ, R., 2012. Cross-cultural differences in the use of discourse markers by Czech and German students of English in the genre of Master's theses. In: C. Berkenkotter, V.K. Bhatia and M. Gotti, eds. Insights into academic genres. Linguistic insights. Studies in language and communication. vol. 160. Bern: Petr Lang, pp. 329-351.

POVOLNÁ, R., 2015. On cross-cultural variation in the use of conjuncts in the research articles by Czech and native speakers of English: Can conjuncts contribute to the interactive and dialogic character of academic texts? In: R. Pló Alastrué and C. Pérez-Llantada, eds. English as a scientific and research language. Debates and discourses. English in Europe, vol. 2, Language and social Life. Berlin and Boston: Mouton de Gruyter, pp. 115-140.

QUIRK, R., GREENBAUM, S., LEECH, G. and SVARTVIK, J., 1985. A comprehensive grammar of the English language. London: Longman.

SCHMIED, J., 2011 . Academic writing in Europe: A survey of approaches. In: J. Schmied, ed. Academic writing in Europe: Empirical perspectives. REAL Studies 5. Göttingen: Cuvillier Verlag, pp. 1-22.

STAŠKOVÁ, S., 2005. Options of identity: Authorial presence in research article abstracts. In: M. Huttová, ed. Slovak studies in English 1. Bratislava: Comenius University, pp. 201-207.

SWALES, J., 1990. Genre analysis. Cambridge: Cambridge University Press.

SWALES, J., 2004. Research genres. Explorations and applications. Cambridge: Cambridge University Press.

TANSKANEN, S.K., 2006. Collaborating towards coherence: Lexical cohesion in English discourse. Amsterdam and Philadelphia: John Benjamins.

VOGEL, R., 2008. Sentence linkers in essays and papers by native vs. non-native writers. Discourse and Interaction, vol. 1 no. 2, pp. 119-126.

VOGEL, R., 2013. Sentence adverbials in academic texts: Preferences of native vs. non-native writers. In: J. Schmied and C. Haase, eds. English for academic purposes: Practical and theoretical approaches. REAL Studies 7. Göttingen: Cuvillier Verlag, pp. 81-93.

WAGNER, S., 2011 . Concessives and contrastives in student writing: L1, L2 and genre differences. In: J. Schmied, ed. Academic writing in Europe: Empirical perspectives. REAL Studies 5. Göttingen: Cuvillier Verlag, pp. 23-48.

\author{
Author's address and contact details \\ doc. PhDr. Renata Povolná, PhD. \\ Department of English Language and Literature \\ Faculty of Education, Masaryk University \\ Poŕíći 9, 60300 Brno \\ Czech Republic \\ E-mail: povolna@ped.muni.cz
}

